\title{
Quantifying Energy Losses on Electric Cooking Stove
}

\author{
Muluken Biadgelegn Wollele \\ School of Mechanical and Industrial Engineering, Debre Markos Institute of Technology, \\ Debre Markos University, \\ Debre Markos, Ethiopia.
}

\begin{abstract}
An electric stove is an integrated electrical heating device to cook and bake. Electric stoves became popular as replacements for solid-fuel stoves which have required more time to cook. However, none deals with quantitative determination of the total minimum heat required or total amount of heat used in specific cooking processes. This paper is aimed to quantify the utilized and lost energy during cooking and give the direction to improve the design or methods to how to minimize the losses to save the energy and cooking time by measuring input energy, utilized energy and energy losses in electric stove. In this test, averagely $0.859 \mathrm{~kW}$ of electric power is consumed in 18 minutes to boil the water. The average, from the total input electric energy, only $0.422 \mathrm{~kW}$ is utilized but more than half of input energy $(0.48 \mathrm{~kW})$ is lost. Thus, the average efficiency of electric stove is $49.1 \%$, which calculated from measured input and utilized energies. Therefore, it is concluded that, this type of stove needs design, manufacturing and material selection improvement to enhance the efficiency.
\end{abstract}

\section{Keywords - Cooking, electric stove, energy utilization}

\section{INTRODUCTION}

Energy is very vital in the generation of wealth and the main factor in economic development [1], [2]. With everincreasing demand for energy and consequent depletion of nonrenewable energy sources, it is imperative to focus attention on increasing efficiencies of all energy utilization processes in terms of energy and time [3].

Energy consumption trend is an important statistic to plan the future energy generation and distribution of a nation. The energy consumption in households in the same way is important for planning and policymaking. Most developed countries have a national statistic that describe the trend in energy consumption [4].

Cooking is one of the most important and necessary household work in every society of the world and it is the most universal residential energy service. Around three quarters of the world greenhouse gas emission is due to inefficient biomass or coal-based cooking in developing countries. Thus, around $50 \%$ of energy for this solid-fuel cooking could be saved by switching to energy-efficient and low-carbon modern cooking appliances with very low costs and high net benefits. However, none deals with quantitative determination of the total minimum heat required or total amount of heat used in specific cooking processes, such as boiling, frying, etc. [5]. Improving the efficiency of cooking offers only incremental reductions in emission. Electric cooking gives zero emissions at the kitchen level and would save lives [6].

An electric stove is an integrated electrical heating device to cook and bake. Electric stoves became popular as replacements for solid-fuel (wood or charcoal) stoves which have required more labor and time to operate and maintain. Electric stoves may have single or multiple cook tops and be controlled by a rotary switch with a finite or infinite number of positions, each of which engages a different combination of electric resistances and hence a different heating power. Some may have a thermostat to switch power on and off and to control the average heating effect of the elements. Electric stoves are widely used in the households and commercial kitchens in Ethiopia.

Over $90 \%$ of energy consumed in household level in Ethiopia is for cooking [7]. There are four heating mechanisms used for food cooking using electric stoves: conduction, convection, radiation and induction. A stove also referred to as a cook top, incorporates one or more distinguishable cooking zones upon which pots/pans can placed. The pots/pan itself can be heated by any of the heating mechanisms (or a mixture) above, before heat is passed to the food via conduction.

Although, it is usual that all the input electric energy did not convert to the useful energy (heat) during cooking. That is why most of electric stoves have thermal efficiency of 51$58.3 \%$ with the fire power of $1 \mathrm{~kW}$ [8]. A lot of studies have been done and in the way and they dealt losses occurred in the electric stove mainly injera baking stove. However, they did not have quantified the basic energy losses and utilized energy in cooking stove that is why this paper mainly focuses on quantifying the major losses occurred on electric stove. Therefore, this manuscript aims to measure input power on electric stove during cooking and quantifying utilized and lost energy. Therefore, this is used for electric stove manufacturers to know the energy losses and useful energy for cooking for further improvement. The welldesigned energy-efficiency household appliance used to reduce unnecessary electricity and fuel consumption. Reducing electricity use reduces fuel combustion in electric power plants [9].

Energy efficient electric stoves have several beneficial consequences: reduce capital investment in energy supply infrastructure, enhance national economic efficiency by reducing energy bills, enhance consumer welfare, empower buyers of electric stove to include energy efficiency (EE) in their choice and decision, strengthen competitive markets, Meet climate-change goals and avert urban/regional pollution.

\section{A. Types of electric stoves}

There are three basic types of electric stoves; solid (Iron hotplates), radiant coil (Open resistor type and Spiral hollow steel tube resistor type) and Ceramic cook top (smooth-top) stoves (Glass-ceramic and Induction stoves). 


\section{B. Spiral hollow steel tube resistor type}

The spiral hollow steel tube has a heating element running through the middle. The tube was wound in a spiral shape and kept at top of the underneath the pan. Unlike iron hotplate, the steel spiral was heated to red heat imparting more heat in a form of conduction and radiation to the pan than the hotplate could. Therefore, this paper investigates the spiral hallow steel tube resistor type electric stove.

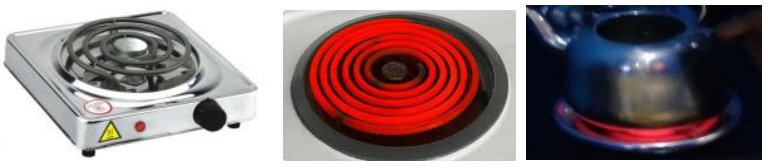

Fig. 1. Electric stove [photograph]

\section{METHODOLOGY}

This paper is aimed to be done by measuring all the input energy, utilized energy and energy losses by using thermocouple on electric stove. Thus, this is used to quantify the main losses existed electric stove during cooking and give the direction to improve the design or methods to how to minimize the losses and save the energy and cooking time.

\section{A. Experimental setup}

This experiment is done by loading one liter of water for boiling by using electric power. Thus, the input power is an electrical energy and output is heat energy which is converted by resistive circuit (twisted coils). In water boiling test experiment, water was heated to boiling point; the time taken to boil a given quantity of water, specific power consumption besides evaluating thermal efficiency is done. The water is boiled and reached temperature of $87^{\circ} \mathrm{C}$ after 18 minutes. Therefore, the electric energy which is loosed for water boiling and utilized energy is measured within 2 minutes' gap by using multimeter and thermocouple respectively.

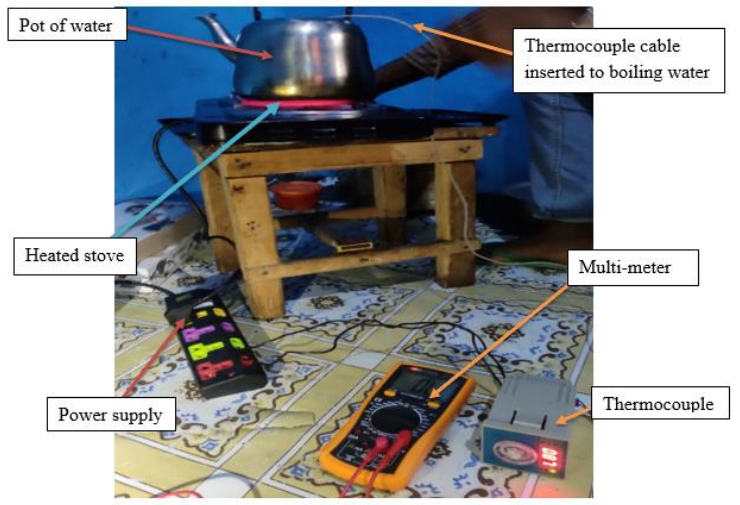

Fig. 2. Experimental setup [photograph]

\section{B. Energy Consumption}

The measurement of energy consumption can be calculated by multiplying the power (watt) and hour of operations. The result will be divided by 1000 and the equation is given below:

Electric consumption (kWh)

$=\frac{\text { power }(\text { Watt }) \times \text { hours of operations }}{1000}$

The voltage and resistance is measured by multimeter to determine the input power for cooking. Power is defined as the rate of energy consumption or conversion within that system- that is, the amount of energy used or converted in a given amount of time. When current flows through a resistive circuit, energy is dissipated in the form of heat. Therefore, it can be determined as follows:

$$
\begin{aligned}
& \qquad P=\frac{V^{2}}{R} \\
& \mathrm{P}=\text { input power, } \mathrm{V}=\text { voltage } \\
& \mathrm{R}=\text { resistance }
\end{aligned}
$$

\section{Utilized heat energy}

Energy consumption in the residential sector represents an important part of total electricity demand. Most consumers are not alert about how to use energy efficiently in their daily lives. In other words, consumers use electric energy inefficiently because they use inefficient electrical appliances. Saving electricity requires either conserving or improving efficiency. Improving energy efficiency (EE) is about choosing the right appliances which use less energy for the same tasks [10]. By making households more energy efficient, the negative impacts on the environment can be reduced. Thus, this study is conducted to test the water boiling by using electric energy.

Energy conversion efficiency is the ratio between the useful output energy (utilized energy) and the input energy. The useful output may be electric power, mechanical work, or heat. As it is observed from figure 1 , the input energy $\left(Q_{i n}\right)$ is electric energy and equal to the sum of the output energy (thermal energy, $Q_{u}$ ) and the losses.

Efficiency of stove $=\frac{\text { utilized energy }\left(Q_{u}\right)}{\text { inpute energy }\left(Q_{i n}\right)}$

Where:

$$
\begin{gathered}
\text { Input energy }\left(Q_{\text {in }}\right)=\text { out put energy }\left(Q_{\text {out }}\right) \\
=\text { Utilized energy }\left(Q_{\mathrm{u}}\right) \\
+ \text { Energy loss }\left(Q_{\mathrm{l}}\right)
\end{gathered}
$$

Utilized energy is properly consumed energy of electric stove for cooking and it is determined as:

$\mathrm{Q}_{\mathrm{u}}=\left(\mathrm{m}_{\mathrm{i}}-\mathrm{m}_{\mathrm{f}}\right) \times \mathrm{C}_{\mathrm{v}}+\left(\mathrm{T}_{\mathrm{f}}-\mathrm{T}_{\mathrm{i}}\right) \times \mathrm{m}_{\mathrm{f}} \mathrm{C}_{\mathrm{p}}$

Where:

$Q_{u}=$ heat utilized $(\mathrm{kJ})$

$m_{i}=$ initial weight of water $(\mathrm{g})$

$m_{f}=$ final weight of water $(\mathrm{g})$

$C_{v}=$ water vaporized heat $(2.260 \mathrm{~kJ} / \mathrm{g})$

$T_{f}=$ final water temperature $\left({ }^{\circ} \mathrm{C}\right)$

$T_{i}=$ initial water temperature $\left({ }^{\circ} \mathrm{C}\right)$

$C_{p}=$ water specific heat $\left(0.004186 \mathrm{~kJ} / \mathrm{g}^{\circ} \mathrm{C}\right)$

The experiment is done by boiling 1liter of water and measuring all the parameters what is needed for this study. To quantify the utilized energy and energy losses, water boiling test was conducted. This test consisted of measuring the required amounts of time, energy to boil up the water and the temperature. Temperature of water is measured with thermocouple. Therefore, it is easy to calculate the energy losses after utilized and input energy is measured.

\section{Energy losses during cooking}

Energy losses occurred during cooking is convection, radiation and conduction mode of heat. The major heat losses found in the system are the convection and radiation heat losses and conduction loss depends on the thermal conductivity of material (pot). As it is shown in the above figure, the stove is exposed with air so that, the major heat 
losses occurred are convection and radiation. Conduction heat loss is occurred due to limited thermal conductivity of pot and convective heat loss depends upon the coefficient of convection of air. The coefficient of convection is dependent on the velocity of air.

\section{Energy loss $\left(Q_{l}\right)=Q_{\text {cond.loss }}+Q_{\text {conv.loss }}+Q_{\text {rad.loss }}$}

(5)

Where:

$Q_{\text {cond.loss }}=$ conduction heat loss

$Q_{\text {conv.loss }}=$ convection heat loss

$Q_{\text {rad.loss }}=$ radiation heat loss

\section{RESULTS AND DISCUSSIONS}

\section{A. Energy consumption}

The electricity consumption cost per household depends on several variables, including family size, number and age of electrical appliances and hours of usage and it is calculated by using above equation. The estimated electricity cost can be determined for different appliances using the power rating of the electrical appliance and its efficiency, usage by number of hours and the domestic tariff rate per kilowatt hour $(\mathrm{kWh})$. The basic thing to reduce the consumption of electricity is using efficient electrical appliances.

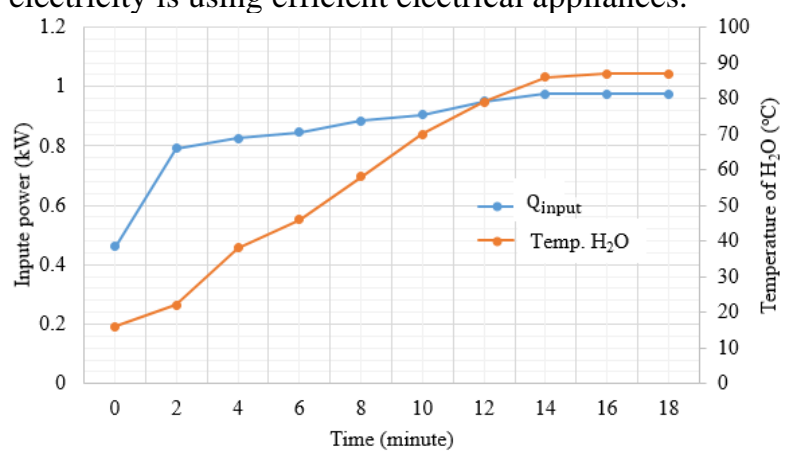

Fig. 3. Energy consumption for boiling water

As it is measured by multimeter, the voltage of electric power supply is 195 volt. It is shown in the fig. 3 that, the energy consumption (input energy) increases as boiling time increases. That is the reason why cooking more time by using electric power leads to cost high electric consumption cost. In this test, averagely $0.859 \mathrm{kilowat}(\mathrm{kW})$ of electric power is consumed for 18 minutes to boil the water. As it is shown in the figure, the temperature of water is constant from 15 to 18 minutes; this indicates the boiling point is $87^{\circ} \mathrm{C}$ for this test. As electric customers told that, for average family number they were cook 3 times per day by using electric stove and it can take averagely one and half hour to finish each cooking. Thus, if they cook with $1 \mathrm{~kW}$ ultimate power stove, they will consume $4.5 \mathrm{kWh}$ of electric power and costs 3.5 Ethiopian Birr (ETB) per day. Therefore, costumer who cooks not baking by using this type of electric stove would pay minimum of 105.39ETB per month. This is high amount of money which is paid only for cooking. This is due to high loss heat energy during cooking. Again think of energy consumption for lighting, baking, washing, television, refrigerator, generally house hold appliance.
Hence, electric consumption can be reduced by using efficient type of house hold appliance basically stove.

\section{B. Energy Utilization}

This study is conducted to investigate by quantify utilized energy and energy loss during boiling of water by using electric stove.

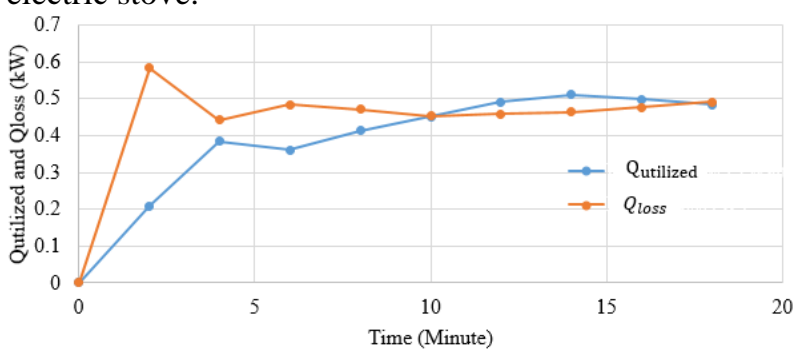

Fig. 4. Energy utilization of stove

As it is shown in fig. 4, there is high energy loss for the first 10 minutes. This is because of input power is continuously rising and it is also dissipated to surrounding. As it was observed from the test, the stove is open and exposed to the surrounding; there is high amount of convection radiation heat loss during cooking. Hence, from 10 to 18 minutes the utilized energy is greater than lost energy. This indicates that, utilized energy for boiling water depends on temperature of water and amount of vaporized water. As temperature of water increases the amount of vaporized water will increase this leads to increase utilized energy. Therefore, while the water is boiling there is high amount of vaporized water. At 2 minute, there is high amount of energy loss because, the temperature of water started from ambient temperature $\left(16^{\circ} \mathrm{C}\right)$ and increases slowly but there is high amount of input electric energy to balance temperature of stove with surrounding. Thus, averagely from the total input electric energy $(0.859 \mathrm{~kW})$ only $0.422 \mathrm{~kW}$ is utilized but, more than half of input energy $(0.48 \mathrm{~kW})$ is lost.

C. Efficiency of stove This experiment is done to investigate the efficiency of electric stove by measuring utilized and lost energy.

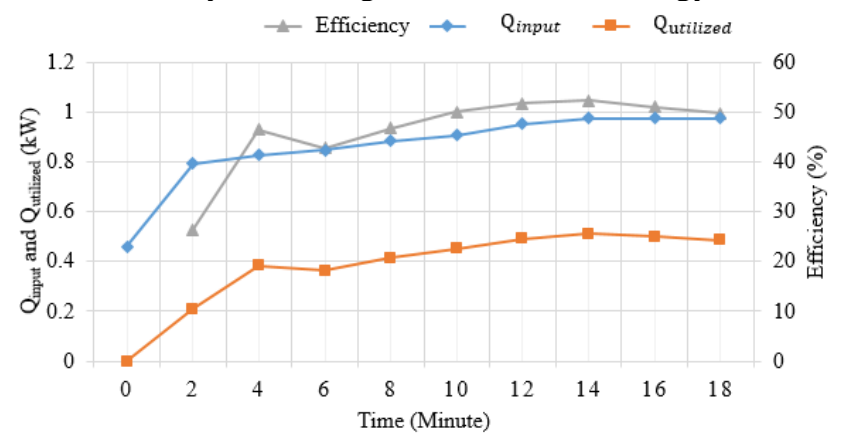

Fig. 5. Efficiency of stove

As it is shown in fig. 5, the efficiency of stove increases as utilized energy increases. The maximum efficiency of this stove is $52 \%$, this is when the water starts boiling. From 14 to 18 minutes the utilized energy is nearly constant, this is due to the temperature of water is constant even if input energy is increasing during boiling which leads to reduce the 
efficiency of stove. Generally, it is calculated that, the average efficiency of electric stove is $49.1 \%$.

\section{CONCLUSIONS}

Electricity based stoves are a sound alternative for the energy inefficient traditional three stone fire stoves. However, also their energy efficiency has to be improved drastically in order to prevent an overload on the electricity stove. In this paper energy

consumption, utilized energy, energy loss and efficiency of stove for boiling 1liter of water by using electric stove was conducted. As it is shown in the result section; electric stove was consumed $0.859 \mathrm{~kW}$ electric power, $0.48 \mathrm{~kW}$ lost energy and $0.422 \mathrm{~kW}$ of utilized energy with efficiency of $49.1 \%$. Thus, the efficiency stove is minimum means that there is high amount of energy loss. Although, this type of stove is mostly used for cooking, so it is highly recommended that, it needs design improvement to minimize the major losses, proper material selection for resistor and pot should be highly conductive to enhance heat transfer and further to increase efficiency of stove.

\section{ACKNOWLEDGEMENT}

The author highly acknowledges his colleagues for providing instruments for test and supporting during experimental test.

\section{REFERENCES}

[1]. M. B. Wollele and A. A. Hassan, design and exeperimental investigation of solar cooker with thermal energy storage. AIMS Energy, 2019. 07(06).

[2]. Fantu Guta, A. D., and Tadele Ferede, The Residential Demand for Electricity in Ethiopia. Environment for Development, April 2015.

[3]. Dilip K. De, N. M. S., Narendra Nath De \& Mathias Ikechukwu Ajaeroh Energy-efficient cooking methods. energy efficiency, 2012. 05(01)

[4]. Ejigu, N. A., Energy Modelling In Residential Houses: A Case Study of Single Family Houses in Bahir Dar City, Ethiopia. thesis, 2014.

[5]. Tejas G. Patil, A. A. P., Dheeraj S. Deshmukh, Experimental Analysis of Helical Coil Induction and Electric Immersion Type Water Heater. International Journal of Science, Spirituality, Business and Technology (IJSSBT), May 2016 Vol. 4(No. 2): p. 4

[6]. Batchelor, S., A technical note on energy consumption. Cooking with electricity in Africa.

[7]. Robin Jones, J. C. D., Leon Simons and Martin Verwaal The Development of an Energy Efficient Electric Mitad for Baking Injeras in Ethiopia Proceedings of the 25th Domestic Use of Energy Conference, 19 December 2017.

[8]. K K Ikpambese, P. A. and T. D. I., Comparative Study of Energy Performance of Kerosene, Electric, Wood and Charcoal Stoves. Int. J. Engg. Res. \& Sci. \& Tech., May, 2014. Vol. 3.

[9]. Stephen Wiel, J. E. M., Governments should implement energyefficiency standards and labels-cautiously. Energy Policy, 2003.

[10]. K. A Rahman, A. M. L., M. Faris Mubin, M. Z. M Yusof, Azian Hariri and M.N.M Salleh, Energy Consumption Analysis Based on Energy Efficiency Approach: A Case of Suburban Area MATEC Web of Conference January 2017. 87.

\section{BIOGRAPHY}

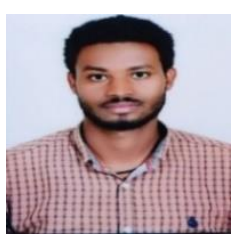

Muluken Biadgelegn Wollele received MSc. degree in Thermal Engineering from Addis Ababa University in 2018 and currently working as Lecturer in school of Mechanical and Industrial Engineering at Debre Markos University, Ethiopia. 